\title{
Dermatological manifestations among diabetic children (0-16) years in jaber abo eliz diabetic center, albulk children hospital, in khartoum, sudan (march, 20I I-march, 20I2)
}

\begin{abstract}
Back ground: Diabetes mellitus (DM) is a major cause of morbidity and mortality Worldwide Diabetes is characterized by a state of relative or complete insulin deficiency, leading to gross defects in glucose, fat, and protein metabolism. Metabolic abnormalities in glucose and insulin relate directly to diabetic thick skin, limited joint mobility, eruptive xanthomas, and acanthosis nigricans (3). Neuropathy, vasculopathy, and immune dysfunction associated with diabetes contribute directly to lower extremity ulcers and certain cutaneous infections (3). A hospital based study was conducted in Khartoum, Sudan at Jaber AboEliz diabetic center (JDC) \& Albuluk children hospital. The aim of this study was to estimate the prevalence of cutaneous manifestations among diabetic children, to find out the relation between the disease duration of DM and glycemic control and between presences of cutaneous manifestations.
\end{abstract}

Patient and method: This is Prospective cross sectional hospital based study, 400children,age less than 16years presented with DM type(1) to Jaber AbuEliz diabetic center and Albuluk hospital in period from June to November 2011. The data was collected by questionnaire to obtain the following: Personal data, duration of diabetes mellitus, Symptoms of skin disease and full dermatological examination, diagnosis was mainly clinically, confirmatory investigations was done in some cases (skin scraping and nail clip for fungal element were done to confirm the diagnosis of tinea capitis, candidal intertrigo and oncychomycosis). The Level of HbAIc was been measured for every patient to assess his glycemic control.

Result: Four hundred diabetic children (54\%males, 46\% female), 328 of them were seen at JDC, 72 of them at Albuluk hospital. Cutaneous manifestations among study group were seen in $23 \%$ of the cases. $22.6 \%$ of patients who had cutaneous manifestation had insulin lipohypertrophy, $14.6 \%$ had xerosis, Limited joint mobility SYNDROME in 9.4\%, 8.3\% had Seborrheic dermatitis, $8.3 \%$ had papular urticaria, $6.3 \%$ had eczema, $3.1 \%$ had abscess, $3.1 \%$ had impetigo, $3.1 \%$ had onychomycosis, $3.1 \%$ had candidal intertrigo, $2.1 \%$ had tinea capitis, $2.1 \%$ had tinea versicolor, $2.1 \%$ had molloscum contagiosum and $2.1 \%$ had insulin lipoartrophy. Forty one percent of patients who had cutaneous manifestations had duration of DM ranging from7-9 yrs. Also, Fifty eight percent of patients who had cutaneous manifestations had level of $\mathrm{Hb} \mathrm{A1C}>11 \%$. So, there is significant relationship between duration of $\mathrm{DM}$ and level of $\mathrm{Hb} \mathrm{A1C}$ and the presence of cutaneous manifestations.

Conclusion: Twenty three percent (23) of patients in this study group had a cutaneous manifestation. There is significant relationship between presence of cutaneous manifestation and $\mathrm{Hb}$ AIc level and disease duration of DM. This study was performed in diabetic children maximum duration of diabetis mellitus is $11 \mathrm{yrs}$, this is may be certainly the reason for absence of cutaneous disorder like (GA, NLD, diabetic dermopathy and diabetic foot ulcer)
Volume 6 Issue 5 - 2017

\author{
Saly Dawoud Hussien, ' Atif AM Saad,' \\ karimeldin MA Salih ${ }^{3}$ \\ 'Dermatologist, $\mathrm{MOH}$, Sudan \\ 2Pediatrics Department, Islamic University of Omdurman, Sudan \\ 3Pediatrics Department, University of Bahri, Sudan
}

\begin{abstract}
Correspondence: Karimeldin Mohamed Ali Salih, MBBS, MD, Pediatrics and Medical Education, College of Medicine,
\end{abstract} University of Bahri, Sudan, Email karimeldin_salih@hotmail.com

Received: January II, 2017 | Published: April 19, 2017

\section{Introduction}

Diabetes mellitus, DM, is metabolic disorder characterized by elevated fasting and postprandial blood Glucose level and a variety of multisystem complications.

Four main types can be distinguished:

Type 1: Also known as insulin-dependent DM, or juvenile-onset diabetes (JOD)

Type 2: Non-insulin-dependent DM, or adult onset diabetes (AOD).

Type 3: Secondary diabetes (SD) is an additional type of diabetes. ${ }^{1}$
Type 4: Gestational diabetes (GD). ${ }^{1}$ Idiopathic type 1 diabetes mellitus is the most common form of childhood diabetes. It affects approximately 1 out of every 600 school-aged children in $2000,{ }^{2}$ according to the World Health Organization, at least 171million people worldwide suffer from diabetes, or $2.8 \%$ of the population. ${ }^{1}$ DM incidence is increasing rapidly, and it is estimated that by 2030 , this number will almost double, ${ }^{3}$ Diabetes mellitus occurs throughout the world, but is more common (especially type 2) in the more developed countries.

The greatest increase in incidence is, however, expected to occur in Asia and Africa, where most patients will probably be found by $2030 .^{3}$ The increase in incidence of diabetes in developing countries 
follows the trend of urbanization and lifestyle changes, perhaps most importantly a "Western-style" diet. This has suggested an environmental (i.e., dietary) effect, but there is little understanding of the mechanism. ${ }^{3}$ Glycosylated hemoglobin (hemoglobin A1c, HbA1c, $\mathrm{A} 1 \mathrm{C}$, or $\mathrm{Hblc}$; sometimes also $\mathrm{HbA1c}$ ) is a form of hemoglobin that is measured primarily to identify the average plasma glucose concentration over prolonged periods of time. It is formed in a nonenzymatic glycation pathway by hemoglobin's exposure to plasma glucose. Normal levels of glucose produce a normal amount of Glycosylated hemoglobin. As the average amount of plasma glucose increases, the fraction of Glycosylated hemoglobin increases in a predictable way. This serves as a marker for average blood glucose levels over the previous months prior to the measurement. The 2010 American Diabetes Association Standards of Medical Care in Diabetes added the $\mathrm{A} 1 \mathrm{c} \geq 48 \mathrm{mmol} / \mathrm{ml}(\geq 6.5 \%)$ as another criterion for the diagnosis of diabetes, ${ }^{4}$ The normal reading range between $4.7-$ $6.3 \%,<7.5 \%$ In diabetes mellitus, is considered as good control, higher amounts of glycosolated hemoglobin, indicating poorer control of blood glucose levels and have been associated with cardiovascular disease, nephropathy, and retinopathy. Monitoring the HbAlc in type1 diabetic patients may improve treatment. In all types of diabetes, abnormalities of insulin and elevated blood glucose levels lead to metabolic, vascular, neuropathic, and immunologic abnormalities. Affected organs include the cardiovascular, renal, and nervous systems, the eyes, and the skin. ${ }^{3}$

\section{Cutaneous manifestations (CM) of diabetes mellitus (DM)}

According to Perez et al approximately $30 \%$ of diabetic patients develop a cutaneous manifestation at some points. ${ }^{5}$ Overall prevalence of cutaneous disorders does not differ between type I and type II diabetics. ${ }^{6}$ Nearly all patients with diabetes have cutaneous findings related to their condition, some diabetes-associated skin conditions are a direct result of the related metabolic changes such as hyperglycemia and hyperlipidemia. ${ }^{7}$ Progressive damage to the vascular, neurologic, or immune systems also contributes significantly to skin manifestations. Metabolic abnormalities in glucose and insulin relate directly to diabetic thick skin, limited joint mobility, eruptive exanthemas, and acanthuses Nigerians. ${ }^{5}$ Neuropathy, vasculopathy, and immune dysfunction associated with diabetes contribute directly to lower extremity ulcers and certain cutaneous infections. ${ }^{5}$ Diabetesassociated skin conditions without a known pathogenesis include: necrobiosis lipoidica, granuloma annular, diabetic dermopathy, acquired perforating dermatosis, and bullosis diabetic rum. ${ }^{5}$ There is also other skin disorders occurs more frequently in diabetic individuals like pruritis, xerosis, vitiligo, lichen planus, finger pebbles and skin tags. ${ }^{6}$ Many skin diseases and insulin-dependent diabetes mellitus have definite HLA associations (Dermatitis herpatoiformis, juvenile dermatomyositis, pemphigus vulgaris). ${ }^{8}$ Hyperglycemia leads to nonenzymatic glycosylation (NEG) of various structural and regulatory proteins, including collagen. Although NEG occurs normally with aging, the process is greatly accelerated in diabetes. NEG leads to the formation of advanced glycation end products (AGEs) that are responsible for decreases in both acid solubility and enzymatic digestion of cutaneous collagen. ${ }^{10}$ Disorders such as diabetic thick skin and limited joint mobility (LJM) are thought to result directly from accumulation of AGEs. ${ }^{11}$

Derangements of immunoregulatory mechanisms also occur in diabetes. $^{2}$ Hyperglycemia and ketoacidosis diminish chemotaxis, phagocytosis, and bactericidal ability of white blood cells. ${ }^{4}$ Historically, infections were a major cause of death in the diabetic patient. This has changed dramatically with improved glucose control and antibiotic use. Despite these improvements, certain infections, such as malignant external otitis, necrotizing soft tissue infections, and the devastating disease of mucormycosis, occur more frequently in patients with diabetes. ${ }^{4}$ Metabolic abnormalities, including hyperinsulinemia, as is seen in early insulin resistant type 2 diabetes, can contribute to cutaneous manifestations as well. The action of insulin on the insulin-like growth factor-1 (IGF-1) receptor appears to mediate the abnormal epidermal proliferation and resulting phenotype of acanthosis nigricans. ${ }^{7}$ And fungal infections (75). Dysregulated lipid metabolism occurs with diabetes-associated insulin deficiency. The activity of lipoprotein lipase (LPL) is directly dependent on insulin, making insulin central to the processing of triglyceride-rich chylomicron and very-low-density lipoproteins. In insulin-deficient diabetic patients, defective lipid processing can lead to massive hypertriglyceridemia, manifesting in the skin as eruptive exanthemas. Naturally, disorders of lipid processing also play an integral role in the vasculopathies of diabetes. ${ }^{8}$ Macro and microangiopathy contribute significantly to the cutaneous complications of diabetes, in patients with diabetes; there is increased "leakiness" or vessel wall permeability, decreased vascular responsiveness to sympathetic innervations, and less ability to respond to thermal and hypoxemic stress. In combination with arteriosclerosis of large vessels, these microvascular abnormalities contribute to the formation of diabetic ulcers. ${ }^{6}$ In addition, a loss of cutaneous sensory innervations occurs with diabetes, predisposing patients to infection and injury. The loss of neuro inflammatory cell signaling plays a causal role in nonhealing lower extremity ulcers. ${ }^{6}$ Few studies was done worldwide to calculate the prevalence of cutaneous manifestation among young diabetic patients; one of this studies was done by Milos D Pavlovic, $\&$ others from Blegrade, Serbia and discovered that $68 \%$ of type 1 IDDM patients (2-20) years have skin manifestation. The commonest manifestation is dry skin or icthyosis (22\%), Acnevulgaris $(19 \%)$, Keratosispilaris $(11 \%)$, fungalinfection $(4.7 \%)$, bacterial infection $(3.3 \%)$, Necrbiosislipoica $(2.3 \%)$. There is significant relationship between prescence of cutanous manifestation and glycemic control (70).

Another study was done in department of dermatology, Rabin medical center, Israel by Osipovich $G$ \& others found $71 \%$ of type 1 IDDM Patients $(0-20)$ have skin manifestations and the most prevalent disease is acquired icthyosis (48\%), scleroderma like skin change $(39 \%)$, Tinea pedis $(32 \%)$, dry scaly palms $(21 \%)$. there is significant relationship between presence of cutaneous manifestation and glycemic control and duration of DM $(70,71)$. Deborah V. Edidin, M.D., Department of Pediatrics, The Evanston Hospital ,Evanston, found that $27 \%$ of diabetic children (0-16) had cutaneous manifestation, there is significant relationship between presence of cutaneous manifestation and glycemic control and duration of DM. lipohypertrophy $(20 \%)$, Pruritis $(10 \%)$, seborrheicdermatits $(9 \%)$, ecezema (4\%), LMJsyndromr (15\%), GA (2\%), bacterial infection $(5 \%)$, fungal infection $(4 \%)(72)$.

Abhishek Goyal, Sujeet Raina, Satinder S Kaushal, Vikram Mahajan, and Nand Lal Sharma, Indira Gandhi Medical College, Shimla, India.found that in $30 \%$ of type 1 diabetic (2_18) years patients had skin lesions.

The common skin disorders were: Xerosis (14\%), diabetic dermopathy (13\%), skin tags (22\%), cutaneous infections (41\%), and seborrheic dermatitis (10\%) (73). Some studies was done in Arab world to estimate the prevalence of cutaneous manifestation among diabetic patients, a retrospective study was carried out at the Princess Haya hospital, Aqaba, Jordan, between August 1998 and April 2000. 
The medical records of all patients visiting the skin clinic during the study period were reviewed. A total of 1195 files were examined. There were 232 patients aged 60years or more with skin disorders. Eczema/ dermatitis was the commonest skin disorder seen a (25.9\% of cases), followed by pruritus without skin lesions $(15.1 \%)$, viral infection (14.7\%, most commonly herpes zoster), fungal infection (13.8\%), and bacterial infection $(10.3 \%)$. Bacterial infection was the commonest skin disorder in patients with diabetes mellitus $(62.5 \%)$, followed by fungal infection $(50.0 \%)$. Skin diseases cause considerable morbidity in elderly people; health promotion and education can do much to reduce the risks of these disorders in the elderly, especially those with diabetes (74). To investigate the prevalence of skin manifestations in diabetic patients attending a diabetic clinic in the Qassim region, Saudi Arabia, a prospective observational study was performed on 320 patients (174 males and 146 females) attending the diabetic clinic. A detailed dermatological examination was carried out by a consultant dermatologist and the cutaneous findings were recorded, the overall prevalence of skin manifestations was $91.2 \%$. Cutaneous lesions were seen in 12 patients $(34.3 \%)$ of type 1 diabetes mellitus (DM) and $280(98.2 \%)$ of type 2 diabetics. There was a statistically significant difference $(\mathrm{p}<0.001)$ in skin manifestations between type 1 and type $2 \mathrm{DM}$ patients. For those patients having diabetes of less than 5years' duration, the incidence of skin manifestations was $80.6 \%$; for those having had diabetes for more than 5years, the incidence was $98 \%$. This difference was statistically significant $(\mathrm{p}<0.001)$. The skin manifestations that had a statistically significant difference $(\mathrm{p}<$ 0.05 ) in prevalence between the 2 durational groups were gangrene, diabetic dermopathy, paresthesia, diabetic feet and diabetic bullae.

\section{Objectives}

The aim of this study was to estimate the prevalence of cutaneous manifestations among diabetic children, to find out the relation between the disease duration, glycemic control and presences of cutaneous manifestation.

\section{Patient and method}

This is Prospective cross sectional hospital based study, conducted in period from June to November 2011, enrolling all children attending Jabir Abu Eliz Diabetic Center and Albuluk hospital. 400 patients, 328 patients from Jabir Abu Eliz Diabetic Center (JDC), 72 patients from Albuluk hospital were seen during the study period. Data was collected every Wednesday from Albuluk hospital and every Monday from Jabir Abu Eliz Diabetic Center. The data was collected by questionnaire to obtain the following: Personal data, duration of diabetes mellitus, Symptoms of skin disease and full dermatological examination, diagnosis was mainly clinically, confirmatory investigations was done in some cases (skin scraping and nail clip for fungal element were done to confirm the diagnosis of tinea capitis, candidal intertrigo and oncychomycosis).

The Level of HbAIc was been measured for every patient to assess his glycemic control by taking two $\mathrm{ml}$ of blood, putting the sample in container which contain EDTA or heparin, shaking for 2 minutes, The $\mathrm{HbAlc}$ result was calculated after 3 minutes as a ratio to total hemoglobin by using a chromatogram known as Mycocard reader 11 the normal reading range between 4.7\%-6.3\%. Statistical analysis was conducted using Statistical Package for Social Sciences (SPSS ver. 19). A descriptive analysis was preformed for all associated parameters. Chi square test was used to measure the degree of association between presence of cutaneous manifestations and between duration of diabetes and glycemic control of the patient, association was considered significant, if $\mathrm{p}$. value is less than 0.05 .

\section{Results}

Twenty three percent of the patients of the study group had cutaneous manifestations twenty two patients $(22.6 \%)$ who had cutaneous manifestation had insulin lipohypertrophy, fourteen patients $(14.6 \%)$ had xerosis, LJM SYNDROME was in nine patients (9.4\%), eight patients ( $8.3 \%$ ) had Seborrheic dermatitis, eight patients $(8.3 \%)$ had popular urticaria, six patients $(6.3 \%)$ had eczema, three patients $(3.1 \%)$ had abscess, three patients $(3.1 \%)$ had impetigo, three patients $(3.1 \%)$ had an onychomycosis, three patients $(3.1 \%)$ had candidal intertrigo, two patients $(2.1 \%)$ had tinea capitis, two patients $(2.1 \%)$ had tinea versicolor, two patients $(2.1 \%)$ had molloscum contagusom, two patients $(2.1 \%)$ had insulin lipoartrophy as shown in Table 1. Forty one percent of patient who had cutaneous manifestation had duration of DM ranged between 7-9yrs, thirty one percent had duration ranged between 4-6yrs. Seventeen percent of them had duration ranged between 10-11yrs. Eleven percent had duration ranged between 0-3yr.p.value:0.000 significant relationship between duration of disease and presence of the cutaneous manifestation, Table 2. Fifty eight percent of patient who had cutaneous manifestation had a level of $\mathrm{Hb} \mathrm{AIc}>11 \%$, thirty six percent had level ranged between $8-10 \%$, six percent had a level ranged between(6-7\%). p.value:0.000 there is a significant relationship between the level HbAIC and the presence of the cutaneous manifestation Table 3. Most of patient who had cutaneous manifestations found in age group ranged between 6-10yrs (48\%) Figure 1. Fifteen patients of those who had insulin lipohypertrophy were in age group $6-10 \mathrm{yr}$, fourteen of them had duration of DM $0-3 \mathrm{yr}$, moderate socioeconomic status was in fourteen patients, seventeen patients had level of $\mathrm{HbAlc}>11$, Eleven mothers of them had primary school education (Table 4). Eighteen patients $(18.7 \%)$ of the study group had cutaneous infections, Eleven patients of those who had cutaneous infection were in age group $6-10 \mathrm{yr}$, ten patients had duration of DM ranged between 7-9yr, fourteen patients had low socioeconomic status, fifteen patients had HbA1c $>11 \%$, eight mothers of them ha (Table 5). All patients of LMJ syndrome were above $14 \mathrm{yr}$ old, eight of them had duration of DM ranged between 10-11yr,six patients had moderate socioeconomic status, eight of them had HbAlc $>11($ Table 6).

Table I The percentage (\%) and frequency of cutaneous manifestation (CM) among study group and among the patients who had CM

\begin{tabular}{llll}
\hline & Frequency & $\begin{array}{l}\text { \% Cm } \\
\text { out of } \\
\text { total } \\
\text { Number } \\
\text { of the } \\
\text { Study }\end{array}$ & $\begin{array}{l}\text { \% } \\
\text { out of } \\
\text { total } \\
\text { Number } \\
\text { of }\end{array}$ \\
& & $\begin{array}{l}\text { Patients } \\
\text { Group }\end{array}$ & With Cm \\
\hline Lipohypertrphy & & $5.50 \%$ & $22.90 \%$ \\
Xerosis & 22 & $3.50 \%$ & $14.60 \%$ \\
Pruritis & 14 & $2.20 \%$ & $9.40 \%$ \\
Limited joint mobility syndrome & 9 & $2.20 \%$ & $9.40 \%$ \\
Papular urticaria & 9 & $2 \%$ & $8.30 \%$ \\
Seborrheic dermatitis & 8 & $2 \%$ & $8.30 \%$ \\
Eczema & 8 & $1.50 \%$ & $6.30 \%$ \\
Lipoatrophy & 6 & $0.50 \%$ & $2.10 \%$ \\
Abscess & 2 & $0.80 \%$ & $3.10 \%$ \\
Impetigo & 3 & $0.80 \%$ & $3.10 \%$ \\
Tinea versicolor & 3 & $0.50 \%$ & $2.10 \%$ \\
Candidal intertrigo & 2 & $0.80 \%$ & $3.10 \%$ \\
Onychomycosis & 3 & $0.80 \%$ & $3.10 \%$ \\
Tinea capittis & 3 & $0.50 \%$ & $2.10 \%$ \\
Molloscum contagosum & 2 & $0.50 \%$ & $2.10 \%$ \\
Total & 2 & $23.20 \%$ & \\
\hline
\end{tabular}


Table $\mathbf{2}$ The duration of diabetes mellitus among patient who had cutaneous manifestation

\begin{tabular}{ll}
\hline $\begin{array}{l}\text { Disease. } \\
\text { Duration }\end{array}$ & $\begin{array}{l}\text { The percentage of patients who } \\
\text { had cutaneous manifestation }\end{array}$ \\
\hline $0-3$ years & $11 \%$ \\
$4-6 y e a r s$ & $31 \%$ \\
$7-9$ years & $41 \%$ \\
$10-1$ lyears & $17 \%$
\end{tabular}

Table 3 The level of $\mathrm{HbAIC}$ among patient who had cutaneous manifestation

\begin{tabular}{ll}
$\begin{array}{l}\text { Hbalc } \\
\text { Level }\end{array}$ & $\begin{array}{l}\text { The Percentage of Patients who had } \\
\text { Cutaneous Manifestation }\end{array}$ \\
\hline 7-Jun & $6 \%$ \\
I0-Aug & $36 \%$ \\
$>11$ & $58 \%$ \\
\hline
\end{tabular}

Table 4 Parameters distribution among patients who had insulin lipohypertrophy

\begin{tabular}{lll}
\hline Parameters & Sub Parameters & $\begin{array}{l}\text { Number of } \\
\text { Patients }\end{array}$ \\
\hline Age & $0-$ Iyr & \\
\hline 2-5yr & 15 \\
\hline 6-I0yr & 7 \\
\hline II-I6yr & 14 \\
\hline Duration of DM & $0-3 y r$ & 4 \\
\hline Socioeconomic status & $4-6 y r$ & 4 \\
\hline & $7-9 y r$ & \\
\hline I0-IIyr & 4 \\
\hline Level of HbAIC & High & 14 \\
\hline & moderate & 4 \\
\hline & Low & \\
\hline Level of education of mothers & $6-7 \%$ & 5 \\
\hline & $8-I 0 \%$ & 17 \\
\hline & $>11 \%$ & 3 \\
\hline Illiterate & 11 \\
\hline Sex & Primary school & 5 \\
\hline & Secondary school & 3 \\
\hline & university & 14 \\
\hline & Male & 8 \\
\hline & Female & \\
\hline & \\
\hline
\end{tabular}

Table 5 Parameters distribution among patients who had cutaneous infections

\begin{tabular}{|c|c|c|}
\hline Parameters & Sub Parameters & $\begin{array}{l}\text { Number of } \\
\text { Patients }\end{array}$ \\
\hline \multirow[t]{4}{*}{ Age } & $0-I y r$ & \\
\hline & $2-5 y r$ & 6 \\
\hline & $6-10 y r$ & II \\
\hline & $11-16 y r$ & I \\
\hline \multirow[t]{4}{*}{ Duration of DM } & $0-3 y r$ & 2 \\
\hline & $4-6 y r$ & 4 \\
\hline & $7-9 y r$ & 10 \\
\hline & $10-11 y r$ & 2 \\
\hline \multirow[t]{3}{*}{ Socioeconomic status } & Low & 14 \\
\hline & moderate & 3 \\
\hline & High & I \\
\hline \multirow[t]{3}{*}{ Level of HbAlc } & $6-7 \%$ & \\
\hline & $8-10 \%$ & 3 \\
\hline & $>11 \%$ & 15 \\
\hline \multirow[t]{4}{*}{ Level of mothers education } & illiterate & 8 \\
\hline & Primary school & 7 \\
\hline & Secondary school & 2 \\
\hline & university & I \\
\hline
\end{tabular}

Table 6 Parameters distribution among patients who had LMJ syndrome

\begin{tabular}{|c|c|c|}
\hline Parameters & Sub Parameters & $\begin{array}{l}\text { Number of } \\
\text { Patients }\end{array}$ \\
\hline \multirow[t]{4}{*}{ Age } & $0-1 y r$ & \\
\hline & $2-5 y r$ & \\
\hline & $6-10 y r$ & \\
\hline & $11-16 y r$ & 9 \\
\hline \multirow[t]{4}{*}{ Duration of DM } & $0-3 y r$ & \\
\hline & $4-6 y r$ & \\
\hline & $7-9 y r$ & 1 \\
\hline & $10-11 y r$ & 8 \\
\hline \multirow[t]{3}{*}{ Socioeconomic status } & Low & 3 \\
\hline & Moderate & 6 \\
\hline & High & \\
\hline \multirow[t]{3}{*}{ Level of HbAlc } & $6-7 \%$ & \\
\hline & $8-10 \%$ & I \\
\hline & $>11 \%$ & 8 \\
\hline \multirow[t]{4}{*}{ Level of mothers education } & Illiterate & I \\
\hline & Primary school & 3 \\
\hline & Secondary school & 5 \\
\hline & University & \\
\hline \multirow{4}{*}{$\begin{array}{r}60.0 \% \\
40.0 \% \\
20.0 \% \\
0.0 \%\end{array}$} & & \\
\hline & & \\
\hline & & - \\
\hline & $6-10 \quad 11-16$ & \\
\hline
\end{tabular}

Figure I Age distribution among patient who had cutaneous manifestation $P$ value $=0.048$.

\section{Discussion}

The cutaneous manifestations of DM can be due to direct result of the related metabolic change such as hyperglycemia or progressive damage to vascular, neurological or immune system. ${ }^{2}$ The prevalence was found to be $23 \%$. This finding is approximately similar to the finding of the Deborah V. Edidin ${ }^{4}$ but less than finding of Milos D Pavlovic ${ }^{7}$ and Yosipovitch. ${ }^{6}$ Forty eight percent of patient who had cutaneous manifestations were in the age group 6-10 yrs, forty one percent of them had duration of DM ranging from 7-9yrs and there is significant relationship between disease duration and presence of cutaneous manifestations. This similar to the finding of Milos Dpavlovic ${ }^{7}$ and Ediden DV. ${ }^{4}$ Fifty eight percent of patients who had cutaneous manifestations had level of $\mathrm{HbA1C}>11$ and this is significant relationship between level of $\mathrm{Hb} \mathrm{Alc}$ and cutaneous manifestations. Similar to this finding was observed by MilosDpavlovic, ${ }^{7}$ Yosipovitch, ${ }^{6}$ EdidenDV. ${ }^{4}$ In this study The commonest cutaneous manifestation was insulin lipohypertrophy (22.9\%), we noticed that most of patient who had lipohypertrophy took the insulin by themselves, the lesion were found in the left upper or lower limbs, Fifteen patients of those who had insulin lipohypertrophy were in age group 6-10yr, fourteen of them had duration of DM 0-3yr, moderate socioeconomic status was in fourteen patients, Eleven mothers of them had primary school education, most of them had $\mathrm{Hb} \mathrm{Alc}>11$ (which can be explained by poor absorption of insulin).

This rate of insulin lipohypertrophy can be explained by two reasons: firstly taking an insulin injection at the site of lipohypertrophy 
will be painless. Secondly, male patient consider this lipohypertrophy as a sign of powerful, ${ }^{7}$ this finding agree with EdidenDV (20\%). ${ }^{4}$ Lipoatrophy was found in $2.1 \%$ of the patients, The cause of the atrophy is unknown, but local deposition of immune complexes that fix complement and release lysosomal enzymes has been reported. ${ }^{8}$ This finding correlate with EdidenDV $(20 \%){ }^{4}$ Eighteen patients $(4.5 \%)$ of the study group had cutaneous infection, bacterial infection represented $(6.2 \%)$ of manifestation: $3.1 \%$ of cutaneous manifestation was abscess, 3.1\% was impetigo. Fungal infection represented $(10.4 \%)$ of manifestation: $3.1 \%$ had onychomycosis, $3.1 \%$ had candidal intertrigo, $2.1 \%$ had a tinea capitis, $2.1 \%$ of had a tinea versicolor.viral infection represented $2.1 \%$ of $\mathrm{CM}$ as molloscum contagusum. Eleven patients of those who had cutaneous infection were in age group 6-10yr, ten patients had duration of DM ranged between 7-9yr, fourteen patients had low socioeconomic status, fifteen patients had $\mathrm{HbAlc}>11 \%$, eight mothers of them were illiterate. Low socioeconomic status and illiteracy of the mothers usually lead to poor hygiene.

Long duration of DM and poor control of blood glucose lead to derangements of immunoregulatory mechanisms (Hyperglycemia diminish chemotaxis, phagocytosis, and bactericidal ability of white blood cells. ${ }^{2}$ All this factors made those patients more prone to develop infections. This finding higher than finding of MilosDpavlovic ${ }^{7}$ and EdidenDV ${ }^{4}$ and lower than finding of Yosipovitch ${ }^{6}$ and Abhishek Goyal. ${ }^{9} 14.6 \%$ of patient had Xerosis. This can be explained by that there is a reduced hydration state of the stratum corneum and decreased sweat gland activity in patients with diabetes which lead to Xerosis(61), This finding lower than finding of Milos D Pavlovic ${ }^{7}$ and similar to finding of Abhishek Goyal. ${ }^{9}$ Limited joint mobility syndrome was found in $9.4 \%$ of the patients, the patients who had this presentation in this study were above 14yrs, had a disease duration $>10$ yrs and $\mathrm{Hb} \mathrm{Alc}>11$. These factors (long duration and poorly control DM) lead to non enzymetic glycation of various structural and regulatory proteins including collagen and this will increase deposition of advanced glycatoin end product in soft tissue of replacement of collagen fiber by it and this mainly the cause of LMJ. ${ }^{10}$ This finding lower than finding of EdidenDV. ${ }^{4}$ Pruritus was found in nine patients (9.4\%). 5 of those patients had a Pruritus localized to shin and 2 to them to the scalp and 2 of them to anogenital region. Localized itching of the scalp and lower extremities was related with Xerosis. The finding correlate with EdidenDV. ${ }^{4} 8.3 \%$ of the patients with cutaneous manifestations had popular urticaria which is hypersensitivity reaction to insect bites, it usually manifested by pruritus excoriated papules usually in exposed parts of the body, This finding does not agree with any one of other studies, this may be due to we are in a subtropical area and the exposure to insect bites is more than other countries. $8.3 \%$ of patients with cutaneous manifestations had Seborrheic dermatitis. in general population Seborrheic dermatitis prevalence is 3-5\%, this high rate can be explain by impairment of immunity in DM that lead to increase (Malassesazia spp) activity which will lead to inflammation and desqumenation, ${ }^{11}$ This finding correlate with EdidenDV ${ }^{4}$ and Abhishek Goyal. ${ }^{9}$ Six $(6.3 \%)$ patients had eczema, three of them had contact dermatitis, two had juvenile planter dermatitis ,one had atopic dermatitis. this can be explain by dehydration of stratum cornum and decrease sweat gland activity and further reduction in lipid lead to increase transpiration relative to environmental water content, loss of integrity of water reservoir of horny layer, chapping and degreasing by industrial or domestic cleaners or solvent, repeated minor truma leading to inflammation and further disorganization of surface aqueslipid balance, ${ }^{2}$ This finding slightly higher than finding of EdidenDV. ${ }^{4}$

In this study we didn't find cutaneous changes like GA, NLD, diabetic dermopathy, foot ulcer but this can be explain by that this study was done in children (0-16), 53.2\% of patients of study group had duration of diabetes mellitus ranged between o-3yrs also $44 \%$ of study population had level of $\mathrm{Hb}$ A1C ranged between 8-10 (not poorly controlled). That change needs a long duration, poorly controlled of blood glucose that leads to microvascular obliteration and necrosis. ${ }^{5}$ Also GA and NLD may be pathogenetically related. It is tempting to speculate that antigenic alteration of basement membrane by glycosylation is implicated. ${ }^{12}$ We didn't find (Dermatitis herpeat iformis, juvenile dermatomyositis, pemphigus vulgaris). Those diseases and juvenile DM have definite HLA associations. ${ }^{13}$

\section{Conclusion}

Twenty three percent of patients in this study group had a cutaneous manifestation. This study was performed in diabetic children (0-16) maximum duration is 11years; this is may be certainly the reason for absence of cutaneous disorder like (GA, NLD, diabetic dermopathy, diabetic foot ulcer). There is significant relationship between presence of cutaneous manifestation and $\mathrm{Hb}$ AIc level and disease duration of DM. Further studies should be performed in other regions in Sudan particularly in areas where there is poor hygiene and no medical service or diabetic centers, to evaluate the prevalence and presentation of cutaneous manifestation there.

\section{Acknowledgments}

None.

\section{Conflicts of interest}

Author declares there are no conflicts of interest.

\section{Funding}

None.

\section{References}

1. Haroon TS. Diabetes and skin---a review. Scott Med J . 2001;19:257-267.

2. Romano G, Moretti G, Di Benedetto A, et al. Skin lesions in diabetes mellitus: prevalence and clinical correlations. Diabetes Res Clin Pract. 1998;39(2):101-106.

3. Bernstein JE. Cutaneous manifestations of diabetes mellitus. Curr Concepts Skin Disord. 2005;1:3.

4. Edidin DV. Cutaneous manifestations of diabetes mellitus in children Pediatr Dermato. 1985;2(3):161-179.

5. Amir Babiker, Vipan Datta. Cutaneous Changes related to insulin therapy. Arch Dis Child. 2011;96: 101-102.

6. Yosipovitch G, Hodak E, Vardi P. The prevelance of cutanous manifestation in young patient with IDDM. Diabetes care. 1999.

7. Milos D Pavolvic, Milen Koyic T, Misovic M. The prevelance of cutanous manifestation in IDDM patients. Diabetes care. 2007;30(8):1964-1967.

8. Bernstein JE. Cutaneous manifestations of diabetes mellitus. Curr Concepts Skin Disord. 2005;1:3.

9. Abhishek Goyal, Sujeet Raina, Satinder S Kaushal, et al. Pattern of cutaneous manifestations indiabetes mellitus. Indian $J$ Dermatol 2010;55(1): 39-41.

10. Najdawi F, Fa'ouri M. Frequency and types of skin disorders and associated diabetes mellitus in elderly Jordanians. Eastern Mediterranean Health Journal. 2002;8(4-5):574-578.

11. Shahzad M, Al Robaee A, Al Shobaili HA, et al. Skin manifestations in diabetic patients attending a diabetic clinic in the Qassim region, Saudi Arabia. Med Princ Pract. 2011;20(2):137-141. 
12. Dogra S, Kumar B. Epidemiology of skin diseases in school children a study from Northern India. Pediatr Dermatol. 2003;20(6): 470-473.
13. Gupta AK, Konnikov N, MacDonald P, et al. Prevalence and epidemiology of toenail onycomycosis in diabetic subjects: a multicentre survey. Br J Dermatol. 1998;139(4):665-671. 